\title{
Combining Mechanical Commutators and Semiconductors in Fast Changing Redundant Inverter Topologies
}

\author{
Armando Cordeiro $^{1,4}$, João Palma ${ }^{2,1}$, José Maia ${ }^{4,5}$, Maria Resende ${ }^{3,4}$ \\ ${ }^{1}$ ISEL - Instituto Superior de Engenharia de Lisboa, (ADESPA), R. Conselheiro Emídio Navarro, 1, 1959-007, Lisboa, PT. \\ ${ }^{2}$ Laboratório Nacional de Engenharia Civil, (CIC), Av. do Brasil, 101, 1700-066 Lisboa, PT. \\ ${ }^{3}$ IST - Instituto Superior Técnico (DEEC), Av. Rovisco Pais, 1, 1049-001, Lisboa, PT. \\ ${ }^{4}$ CIEEE - Center for Innovation in Electrical and Energy Engineering \\ ${ }^{5}$ Escola Superior de Tecnologia de Setúbal, (DEE), Estefanilha, 2914-508 Setúbal, PT. \\ Email: acordeiro@deea.isel.ipl.pt; jpalma@lnec.pt; jose.maia@estsetubal.ips.pt; mresende@ist.utl.pt
}

\begin{abstract}
This paper presents some solutions for fast changing and "soft" commutation between main and redundant branches in fault-tolerant inverter topologies through the combination of mechanical commutators and semiconductors. The present study deals with redundant two-level three-phase voltage-source inverters. Experimental results confirm the validity of the proposed solutions.
\end{abstract}

Keywords - power electronics reliability, fault-tolerant inverter, voltage source inverter (VSI), IGBT failure, mechanical commutator, converter redundancy.

\section{INTRODUCTION}

Failures in power electronics converters are a concern since they are largely used in industry [1]. Each particular application has different requirements regarding fault tolerance in the energy processing system, but the problem has special importance in safety related applications and in highly sensible equipment. Medical, aerospace, automotive, military and other industries needing high availability power supplies or special machine tool drives are within the most demanding applications in terms of reliability of power electronics equipment.

Reliability improvement may be achieved in different ways, e.g. by providing over rated or more reliable components, using redundant design, or adopting automatic changes in the control strategy; these can be used either individually or in combination. Fault-tolerant systems must be able to proceed in operation (fully or in a degraded mode) in the event of one or more failures.

Entire reliability chains have to be taken into account in the analysis and design of dependable power electronic systems, namely: controllers, gate drive circuits, sensors, power semiconductors, auxiliary power supplies, passive elements (power capacitors, connectors, switches, pcbs), fans, etc. Traditional mathematical models (such as fault trees or Markov chains) can be used for global dependability evaluation, given that specific reliability data and analysis tools are available for each element in the chain. Attempts to improve reliability should then be addressed to the most vulnerable parts.
A number of special converter structures have been proposed for fault-tolerant machine drives. This paper will focus only on those based on two-level voltage-source bridge inverters with IGBT devices:

- some rely on specific control strategies for acceptably degraded performance in the event of a failure yielding the loss of devices, e.g. [2-5].

- other schemes promote the insertion of standby branches or connections with new devices; some of these also need changes in the control for post-fault operation, e.g. [6,7].

A comparison of some of these different solutions regarding features, cost and limitations is given in [8].

Applications involving electrical drives, where fault transients are to some extent filtered by the machine and mechanical load, have also been object of extensive research, especially in terms of fault-tolerant converter-machine associations, as reported in [9-13], namely by modifying either the machine design or the converter structure and control, or even promoting full redundant converter-machine associations.

An appreciable number of studies have been devoted to modeling, predicting and improving power semiconductors reliability [14-16]. Others were dedicated to power modules degradation due to thermomechanical cycling stress and fatigue $[17,18]$.

Redundant converter topologies as general purpose structures do not seem fully explored in terms of minimising transients in the change over process.

The present study is focused on the power stage of a two-level three-phase voltage-source inverter, by proposing and analysing some solutions for redundant topologies with fast switch over, as well as attempting to make their performance and reliability evaluation. Both power supply and load faults are not subject of study in this paper. Some redundant solutions will be proposed next allowing prompt replacement of faulty devices by new ones with the help of mechanical commutators. Solutions for acelerating the operation and arc extinction in these devices are then presented and supported by experimental tests. 


\section{Proposed TOPOlOGIES For FAUlt TOLERANCE}

Most of the existing fault tolerant solutions are dedicated to specific load types, i.e. machine drives. The redundancy schemes proposed in the following aim at achieving high reliability in converters for general purpose.

Compared to power semiconductors, mechanical commutators are rather slow but minimise losses and may perform total isolation and stress elimination to redundant devices. They can still be used in combination with semiconductors to provide "soft" commutation, as suggested in the redundancy schemes shown in fig. 1. No violent current extinction occurs in these circuits, where additional diodes play the temporary role of diverting currents during the commutation process. The mechanical switching time can be normally about $15 \mathrm{~ms}$ but it can also be significantly reduced by applying an initial peak overcurrent to the contactor's solenoid. Basic inverter redundant solutions presented in fig. 1 allow to isolate a faulty device either in open- or in short-circuit.

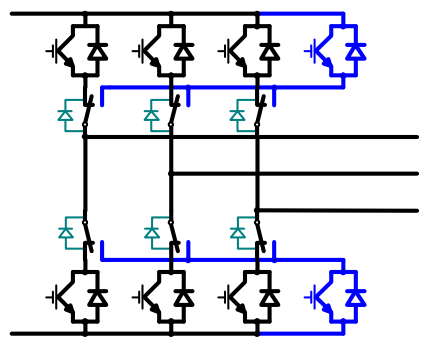

(a) standby redundancy of one device for three in service.

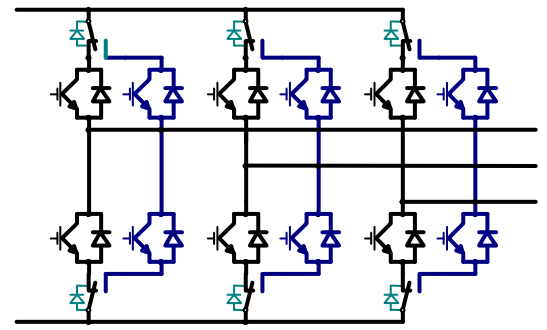

(b) standby redundancy of one branch for one in operation.

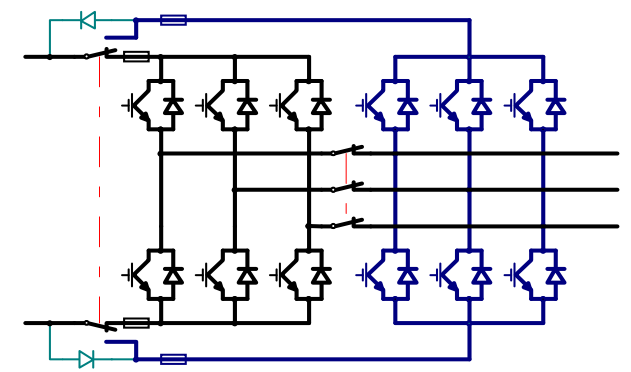

(c) full bridge redundancy (the right side bridge is in quasi standby, with voltage stress).

Figure 1. Redundancy schemes for three-phase bridge VSI using mechanical commutators with soft commutation.

The circuit of fig. 2 has additional IGBT devices to be used while commutators have not yet operated allowing to proceed immediately the operation with the standby inverter bridge (right) in the event of an open-circuit failure in a device of the main bridge. Unfortunately this scheme does not allow faster isolation of shorted devices in the main bridge (left): contactor $\mathrm{K} 2$ has to open first.

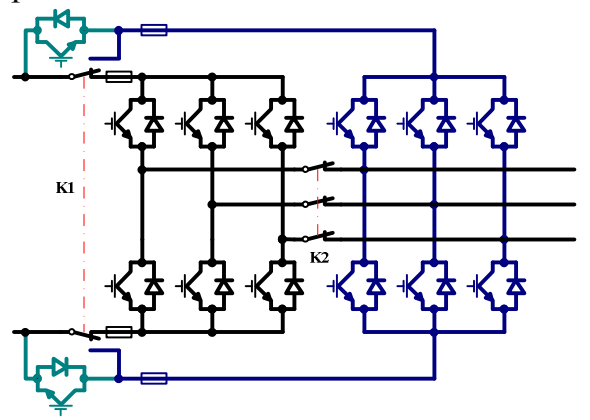

Figure 2. Full redundancy scheme for a three-phase bridge voltagesource inverter with fast commutation capacity in the event of an IGBT failure in open-circuit mode.

The solution proposed fig. 3-(a) is intended for fast isolation of faulty devices in both modes, using fuse blowing at the load side of the main inverter, with the aid of an auxiliary circuit composed of six diodes and two IGBT devices.

Fig. 3-(b) presents the same solution using now thyristors in the auxiliary circuit. Details of the isolation process after a shorted device in the main bridge can be seen. Additional resistors (e.g. R1, R2) can be used to test the auxiliary circuit. In case of short-circuit fault and immediately after the fault isolation can be launched the standby inverter bridge and the contactor K1. For open-circuit fault the standby inverter bridge and the contactor $\mathrm{K} 1$ can be launched immediately.

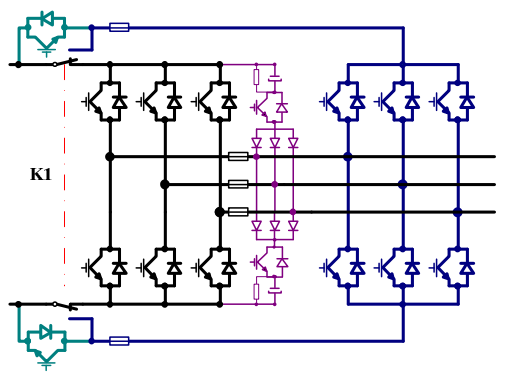

(a) Auxiliary circuit for fault isolation using IGBT-diode devices.

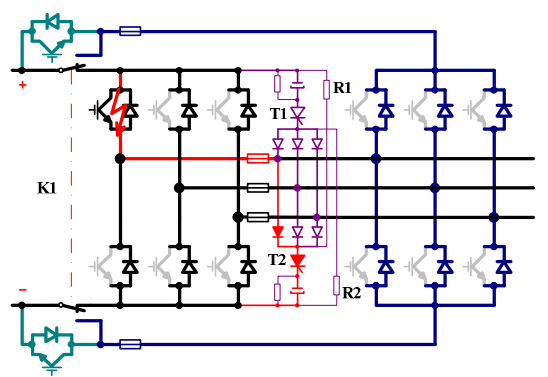

(b) Auxiliary circuit for fault isolation with thyristors.

Figure 3. Full redundancy scheme for a three phase bridge VSI with fast commutation capacity in the event of an IGBT failure in either open-circuit or short-circuit mode. 


\section{Simulation RESUltS}

In order to show the effects of combining mechanical commutators and semiconductors in fast changing redundant inverter topologies, the simulation of the redundant scheme of fig.1a is presented. A three-phase induction motor was included as the critical load. The redundant inverter scheme, fault logic decision algorithm, three-phase induction motor and respective space vector modulation (SVM) current mode control were modelled in Matlab-Simulink.

The simulation of an open-circuit failure, at $\mathrm{t}=0.8 \mathrm{~s}$ with $12 \mathrm{Nm}$ of imposed mechanical load, is presented at fig. 4. It can be seen the temporary loss of current $\left(i_{l}\right)$ in the faulty leg and the switching of currents between main $\left(i_{M}\right)$ and redundant $\left(i_{R}\right)$ branches. A maximum detection and switching time period of $10 \mathrm{~ms}$ was considered. After this period, the SVM current mode control maintains the current, torque and speed within the desired value.
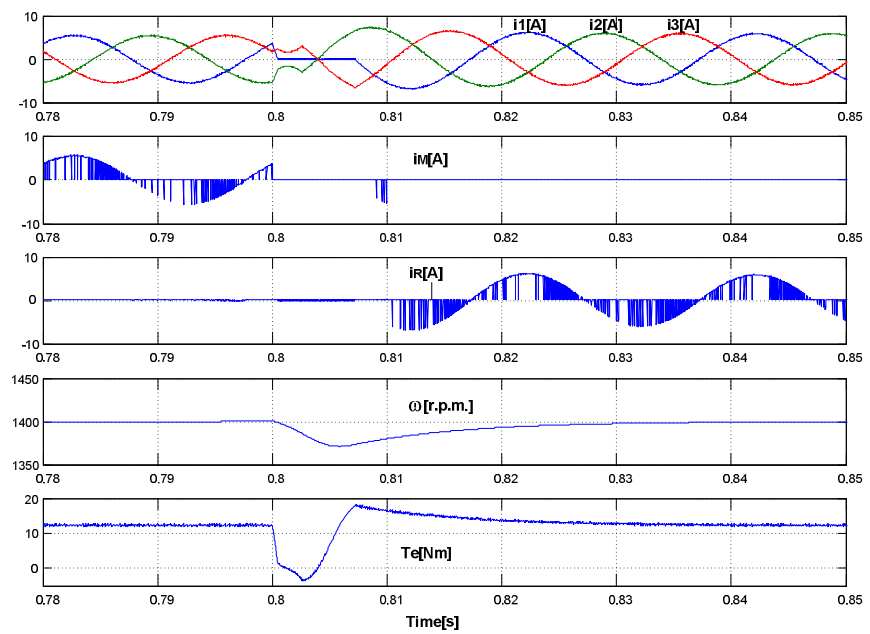

Figure 4. Simulation results for the redundant scheme of fig.1a with a threephase IM having $12 \mathrm{Nm}$ of mechanical load and SVM current control. A Single open-circuit failure is introduced at $\mathrm{t}=0,8 \mathrm{~s}$. Stator currents $(i 1, i 2, i 3)$, current in the main branch $\left(i_{M}\right)$, current in the redundant branch $\left(i_{R}\right)$, angular mechanical speed $(\omega)$ and electromagnetic torque $(\mathrm{Te})$ are shown.

\section{Mechanical Commutation Tests}

In this section some experimental tests to $\mathrm{AC}$ mechanical commutators are presented, showing the effect of switching DC currents. This detail is particularly important for the overall performance of the proposed fault tolerant schemes and was the central object of the tests conducted so far.

Most industrial contactors are typically designed to withstand $\mathrm{AC}$ currents and the switching process is mostly facilitated by its interruptions in each half cycle. When used with DC currents, the arc extinction between contacts is very hard and leads normally to much higher contactor damage. Often DC arc extinction using external magnetic field is used.

Exploring the use of AC contactors with DC currents is an interesting issue since these devices present some advantages, namely: cost, weight and volume. Excessive weight and volume is usually synonymous of slow mechanical commutations. These aspects are particularly important in applications that require fast switching; as usually happens with safety related applications.

In order to increase the speed of the switching process an auxiliary accelerator circuit is proposed (see fig. 5-(a)). In this scheme a 3-phase contactor designed for $3 \mathrm{~kW} / 400 \mathrm{~V}$, with control supply voltage of $30 \mathrm{Vdc}$ was accelerated by applying an initial peak overcurrent to the contactor's solenoid. The contactor chosen has NO (Normally Open) and NC (Normally Closed) electrical contacts available.

In this paper an $\mathrm{RCD}$ auxiliary snubber circuit $\left(\mathrm{R}_{\mathrm{aux}}=10 \mathrm{k} \Omega\right.$, $\mathrm{C}_{\mathrm{aux}}=5,5 \mu \mathrm{F}, \quad \mathrm{D}_{\mathrm{aux}}-$ Fast Recovery Diode $\quad \mathrm{V}_{\mathrm{RRM}}=600 \mathrm{~V}$; $\mathrm{I}_{\mathrm{F}(\mathrm{AV})}=10 \mathrm{~A}$ ) is also proposed (see fig. 5-(b)) to facilitate the arc extinction, and to promote a soft-switching commutation of DC currents. An experimental test with variable DC voltage and RL load was designed to evaluate the performance of electrical contacts with auxiliary snubber circuit.

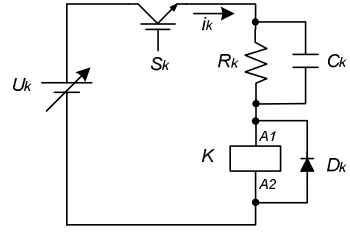

(a)

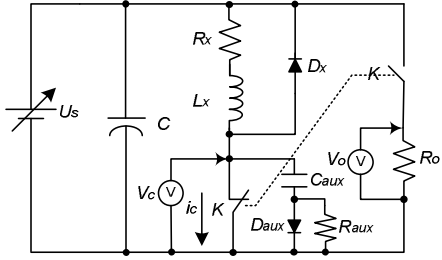

(b)
Figure 5. Auxiliary accelerator circuit designed to increase the speed of the switching process.

Experimental results of both circuits are presented next. In all the following results the following quantities are represented: $i_{k}$ - current of contactor's solenoid (see fig. 5-(a)), $V c$ - voltage of NC contacts, $V o$ - voltage on the branch of NO contacts, and $i c$ - current through NC contacts (all seen in fig. 5-(b)). The oscilloscope channels follow the same order.

Experimental results with and without auxiliary accelerator, both with snubber circuit can be seen in fig. 6 . Using auxiliary accelerator circuit and snubber circuit, the current in the $\mathrm{NC}$ contact is deviated in about $0.4 \mathrm{~ms}$. The $\mathrm{NC}$ contacts takes about $8 \mathrm{~ms}$ to open and the NO takes about $9 \mathrm{~ms}$ to close (fig. 6(a)). Without auxiliary accelerator circuit, electrical contacts take about 16ms (NC) and 20ms (NO) (fig. 6-(b)).

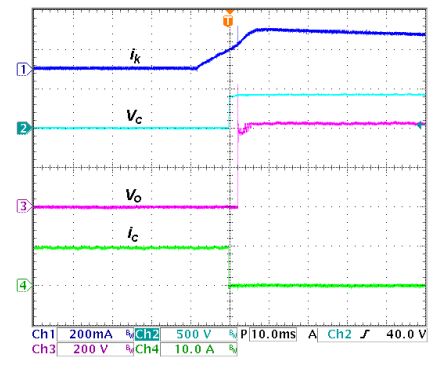

(a)

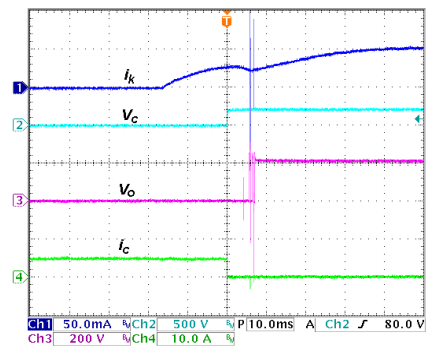

(b)
Figure 6. Experimental results: (a) with $400 \mathrm{Vdc} / 10 \mathrm{~A}$ using both auxiliary accelerator and snubber circuit; (b) with $200 \mathrm{Vdc} / 5 \mathrm{~A}$ and without auxiliary accelerator circuit. 
Note that the common AC industry grade contactor was used. One specifically designed for this type of application (i.e. for diverting instead of extinguishing currents, and having lower inertia in the moving part) is expected to produce even better results.

An experimental result without snubber circuit can be seen in fig. 7. The time to switch over and the presence of arc in contact are now more evident. Above certain DC voltage/current ratios, arc extinction is not feasible. Notice the increase of electromagnetic interference in other circuits due to electric arc in contacts.

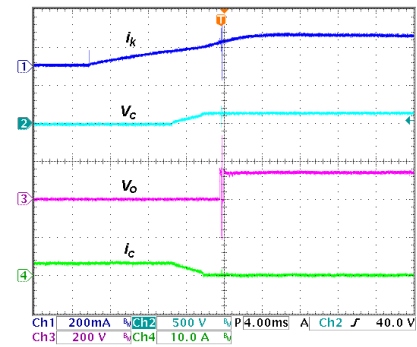

(a)

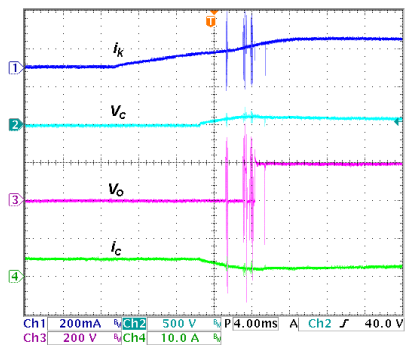

(b)
Figure 7. Experimental result without snubber circuit: (a) at $150 \mathrm{Vdc} / 4 \mathrm{~A}$ is clear the presence of electric arc in contacts together with switch over time increasing; (b) at $200 \mathrm{Vdc} / 5 \mathrm{~A}$ arc extinction and switch over not reachable.

\section{CONCLUSIONS}

In this paper some solutions for redundant topologies with fast switch over were proposed and analysed, focusing on the power stage of two-level three-phase voltage-source inverters. Experimental results revealed that under usual conditions and without auxiliary circuits, the switch over of DC currents is impractical. However using improved circuits it is possible to perform a reliable and fast commutation, meeting the specific requirements of most safety related applications.

The combination of mechanical commutators (contactors) and redundant power devices allow exploring other strategies to overcome main device failure modes. The use of contactors is an economic and safe solution for isolating shorted devices within converters. Additional diodes play an important role of diverting currents during the commutation process allowing a "soft-switch" operation mode of redundant schemes. The use of semiconductor switches instead of contactors would increase converter permanent losses and heat removal needs, while creating additional failure prone elements under stress.

The proposed solutions have some disadvantages, such as increased costs due to redundant power devices or branches, additional auxiliary circuits or even some degree of voltage stress in certain redundant topologies. These disadvantages are the natural result of the increased fault tolerance.

The results obtained so far and presented in this paper allow to face with optimism the experimental implementation of faulttolerant converter topologies combining mechanical commutators and semiconductors in fast changing solutions.

\section{REFERENCES}

[1] Kastha, D.; Bose, B.; "Investigation of Fault Modes of Voltage Fed Inverter System for Induction Motor Drive,"; IEEE Transactions on Industry Applications, Vol. 30, No 4, July/August 1994, pp.1028 1038.

[2] Spée, R., Wallace, A.K.; "Remedial strategies for brushless DC drive failures." IEEE Trans. Ind. App., Vol.26 №2, March/April 1990. pp. $259-266$

[3] Liu, T., Fu, J.; Lipo, T.A.; “A strategy for Improving Reliability of Field Oriented Controlled Induction Motor Drives." IEEE Trans. on Ind. App., Sep./Oct. 1993: Vol. 29, Nº5, pp. 910-918

[4] Van der Broeck, H. W.; Van Wyk, J. D.; "A Comparative Investigation of a Three-Phase Induction Machine Drive with a Component Minimized Voltage-Fed Inverter under Different Control Options." IEEE Transactions on Industry Applications, Vol. IA-20 Issue: 2, March 1984, pp. 309-320.

[5] Ribeiro, R., Jacobina, C.; Lima, A.; Silva, E.; "A strategy for improving Reliability of Motor Drive Systems Using a Four-Leg Three-Phase Converter." 16th Annual APEC 2001. Anaheim, California, E.U.A. March 2001. pp.385-391; ISBN: 0-7803-6618-2.

[6] Ribeiro, R.; Jacobina, C.; Silva, E.; Lima, A.; "A fault tolerant induction motor drive system by using a compensation strategy on the PWM-VSI topology." IEEE 32nd Annual Power Electronics Specialists Conference, PESC. 2001, 17-21 Junho. Vancouver, BC , Canada: 0-7803-7067-8, 2001. pp. 1191 - 1196 vol.2.

[7] Corrêa, M.B.R., C.B. Jacobina, E.R.C. da Silva, e A.M.N. Lima. "An Induction Motor Drive System with Improved Fault Tolerance." IEEE Trans. Ind. App., May/June 2001: vol.37; N. ${ }^{\circ} 3$; pp.873-879.

[8] Welchko, B.A.; Lipo, T.A.; Jahns, T.M; Schulz, S.E.; "Fault tolerant three-phase AC motor drive topologies: a comparison of features, cost, and limitations." IEEE Transactions on Power Electronics, July 2004: Vol.19, No 4, pp.1108-1116.

[9] Welchko, B.A.; Lipo, T.A.; "A Novel Variable-Frequency ThreePhase Induction Motor Drive Using Only Three Controlled Switches." IEEE Transactions on Industry Applications, Vol.37, N 6 ., Nov./Dec 2001, pp. 1739-1745.

[10] Yeh, Chia-Chou; Demerdash, Nabeel A. O.; "Fault Tolerant Operations in Adjustable-Speed Drives and Soft Starters for Induction Motors." IEEE Power Electronics Specialists Conference, PESC 2007. Orlando, Florida, USA. pp.1942-1949, October 2007.

[11] Ertugrul, N., W. Soong, G. Dostal, e D. Saxon. "Fault tolerant motor drive system with redundancy for critical applications." IEEE 33rd Annual Power Electronics Specialists Conference. PESC 02. 7 Nov. 2002. 0-7803-7262-X, pp. 1457 - 1462, vol.3.

[12] Jahns, T.M.; "Improved Reliability in Solid-State AC Drives by means of multiple independent phase-drive unit," IEEE Transactions on Industrial Applications, Vol.16, pp.321-331, May/June 1980.

[13] Fu, Jen-Ren., and Thomas A. Lipo. "Disturbance-Free Operation of a Multiphase Current-Regulated Motor Drive with an Openen Phase." IEEE Tran. Ind. App., Vol.30, N5, Sept/Oct. 1994, pp. 1267-1274.

[14] Bailey, C.; Lu, H.; Tilford, T.; "Predicting the Reliability of Power Electronic Modes," 8th International Conference on Electronic Packaging Technology, ICEPT 2007, pp. 1-5, August 14-17, 2007, Shanghai, China.

[15] Stoyanov, S.; Bailey, C.; Lu, H.; Cross, M.; "Solder Joint Reliability Optimization," APACK 2001, Conference on advances in packages, Singapore, pp.178-186.

[16] Ciappa, M.; Fichtner, W.; "Lifetime Prediction of IGBT Modules for Traction Applications," 38th Annual International Reliability Physics Symposium, San Jose, California, 2000, ISBN 0-7803-5860-0.

[17] Xiong, Y.; Cheng, X.; Shen, Z. J.; Mi, C.; Wu, H.; Garg, V.; "Prognostic and Warning System for Power-Electronic Modules in Electric, Hybrid Electric, and Fuel-Cell Vehicles," IEEE Transactions on Industrial Electronics, Vol.45. No6, pp.2268-2276, June, 2008.

[18] Bouarroudj, M.; Khathir, Z.; Ousten, J. P.; Dupont, L.; Lefebvre, S.; Badel, F.; "Comparison of stress distribution and failure modes during thermal cycling and power cycling on high power IGBT modules," European Conference on Power Electronics and Applications, 2-5 Sept. 2007, Aalborg. ISBN-978-92-75815-10-8. 